\title{
Dynamical Model for an Interharmonic Property of a Piezoelectric Bimorph Cantilever Beam with Self-Sensing Function
}

\author{
Ting Zhang, Ying Pan, and Lijie Cao \\ College of Mechanical Engineering, Shanghai University of Engineering Science, Shanghai 201620, China \\ Correspondence should be addressed to Ting Zhang; ztwcl@sjtu.edu.cn
}

Received 3 May 2016; Revised 30 July 2016; Accepted 2 August 2016

Academic Editor: Mickaël Lallart

Copyright (c) 2016 Ting Zhang et al. This is an open access article distributed under the Creative Commons Attribution License, which permits unrestricted use, distribution, and reproduction in any medium, provided the original work is properly cited.

A piezoelectric bimorph cantilevered beam is analyzed dynamically by a longitudinal and transverse coupling theory. When a sinusoidal voltage is applied on the actuating layer of the bimorph, the output voltage of the sensing layer appears as interharmonic component signal. The interharmonic frequency is noninteger harmonic frequency of the applied voltage. A dynamic model is proposed to describe the interharmonic property of the piezoelectric bimorph beam. Through some simulations and experiments, the theoretical model is verified effectively to express the nonlinear characteristic. Furthermore, when the piezoelectric bimorph resonance happens, some interharmonic response at low frequency will modulate with the resonance response.

\section{Introduction}

Piezoelectric materials have been widely applied to many practical areas. The bimorph, which consisted of two pieces of piezoelectric patches bonded symmetrically on the top and bottom of a copper electrode beam, has been used as electroacoustic transducer, energy harvester, micropump driver, and microrobot for its sensitive response characteristics. For example, a bimorph impedance transducer was utilized as a simultaneous actuator and sensor for mechanical impedance measurement [1], an electromechanical piezoelectric bimorph beam with a tip mass as a power harvester under two input base transverse and longitudinal excitations extracts energy from the vibration system via piezoelectric transduction [2], and a circular piezoelectric bimorph for a micropump driver was optimized by a finite-element method [3]. However, before the piezoelectric bimorph can be used in these fields, it is necessary to study its actuating and sensing properties.

A significant number of works have thus focused on modeling the electromechanical coupling characteristics of the piezoelectric bimorph. By a finite element method the static and dynamic analysis of a piezoelectric bimorph was implemented [4], using a spectral finite element method for bimorph piezoelectric beam energy harvesters that was developed based on the Timoshenko beam theory and the Euler-Bernoulli beam theory [5], and a finite element model was developed and used to evaluate the accuracy of the analytic model for a bimorph cantilever undergoing asymmetric sensing and actuation [6], and a finite element method for a piezoelectric bimorph was used to account for the changes in physical properties of the membrane strip at the location of the piezoelectric bimorph [7]. Except for the finite element model, other methods were adopted to represent the piezoelectric bimorph mathematically; for instance, the mechanical equivalent spring mass-damper model and the electric equivalent circuit model for a piezoelectric cantilever bimorph energy harvester were compared [8], a distributed parameter piezoelectric bimorph cantilever energy harvester was modeled by an Euler-Bernoulli theory combined with the modal expansion theorem [9], a closedform analytical solution was presented for a piezoelectric unimorph cantilever under base excitation based on the Euler-Bernoulli beam assumptions with Rayleigh-Ritz discretization [10], and an efficient spectral element with electric potential degrees of freedom was proposed to investigate 


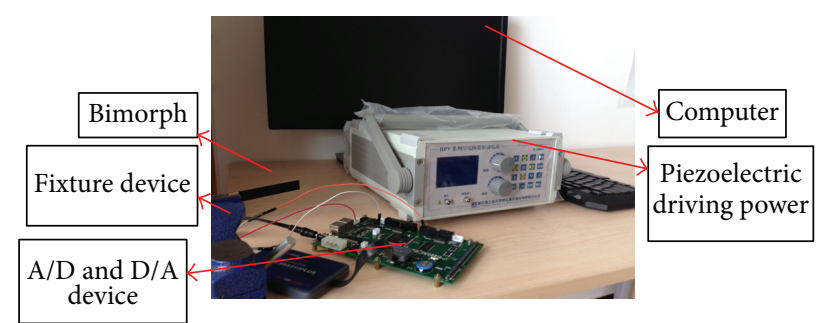

FIGURE 1: A vibration measure system for a piezoelectric bimorph.

the static electromechanical responses of a piezoelectric bimorph for its actuator and sensor functions [11]. However, the piezoelectric bimorph has inherent nonlinear property; macrofiber composite-based bimorph actuators inherited the nonlinear properties of hysteresis and creep of piezoelectric materials and were modeled with a hybrid model including a generalized Maxwell slip operator and a creep operator [12] and a nonlinear mathematical model for the spacecraft coupled by the hub-bimorph mechanism was developed [13].

Vibratory energy harvesters (VEHs) have been developed to exploit the sensing ability of smart materials by the electromechanical mechanisms under external vibrations. Some designed miniaturized VEHs were capable of harnessing energy efficiently from low frequency excitations. Additionally, purposeful introduction of nonlinearities into the dynamics has been investigated to enhance the broadband transduction [14]. Moreover, for a piezoelectric vibration energy harvester at suitable mechanical excitation, a nonlinear frequency-up conversion mechanism could widen the equivalent bandwidth of the piezoelectric energy converter [15].

This paper investigates a different phenomenon, namely, the interharmonic $[16,17]$ resonance property of a piezoelectric bimorph for the purpose of energy harvesting under low frequency excitations. Figure 1 shows a vibration response measure system for a piezoelectric bimorph, whose end is fixed with the fixture device. The piezoelectric actuating layer is applied with a sinusoidal voltage from the driving device controlled by the $\mathrm{D} / \mathrm{A}$ circuit, while the piezoelectric sensing layer outputs harmonic voltage due to the stress from the actuated bending deformation. The output harmonic voltage is saved by the computer through the A/D circuit. Figure 2 gives the harmonic voltage signal and frequency response by the Fast Fourier Transform when a sinusoidal voltage at amplitude $4.5 \mathrm{~V}$ and frequency $1.4 \mathrm{~Hz}$ is applied on the actuating layer. The output voltage is shown in Figure 2(a), and it indicates a modulated wave signal which includes many frequency sinusoidal signals. Figure 2(b) displays the magnitude-frequency characteristics of the output voltage, and it is manifested that the output voltage has multiple interharmonic components, and the first four frequencies are $1.404 \mathrm{~Hz}, 2.698 \mathrm{~Hz}, 5.507 \mathrm{~Hz}$, and $6.801 \mathrm{~Hz}$, respectively. Therefore, it is necessary that this interharmonic property of the piezoelectric bimorph is described mathematically and accurately before it is widely used in a variety of areas.
The rest of this paper is organized as follows: In Section 2, the interharmonic property model of the piezoelectric bimorph cantilevered beam is introduced. In Section 3, the simulation and experiment results are shown, and some discussions are focused. Finally some conclusions are given in Section 4.

\section{Dynamical Model for a Piezoelectric Bimorph Cantilever Beam}

Figure 3 shows a piezoelectric bimorph cantilever beam. The left end of the beam is fixed and the right end is free. Moreover, the layers above and below are the piezoelectric (PZT) material and the middle layer is a copper electrode. $l_{b}$ and $h_{b}$ are effective length and height of the cantilever beam, respectively. Furthermore, $h_{e}$ is height of the electrode and $x_{p}$ is the distance from the fixture to the piezoelectric materials. The bimorph is mainly used to detect and suppress vibration signal for space structures. Therefore, the sensing property integrated with actuating function of the piezoelectric bimorph will be modeled by some dynamic analyses.

An infinitesimal element method is proposed to model the nonlinear bifurcation property for the bimorph shown in Figure 4. $N, Q$, and $M$ are the axial force, the shear force, and the bending moment, respectively. Moreover, $\theta$ is the angle between the $x$-axis and the center axis of the bimorph. And $d s$ is the length of the infinitesimal element. " $a$ ", "e," and " $s$ " represent "actuating layer," "electrode layer," and "sensing layer," respectively. A set of equations is gained by force balance principle and is expressed as

$$
\begin{aligned}
& \left(N+\frac{\partial N}{\partial s} d s\right) \cos \left(\theta+\frac{\partial \theta}{\partial s} d s\right)-N \cos (\theta) \\
& +\left(Q+\frac{\partial Q}{\partial s} d s\right) \sin \left(\theta+\frac{\partial \theta}{\partial s} d s\right)-Q \sin (\theta)-c \dot{u}_{x} \\
& \quad+f_{x}=d m \ddot{u}_{x}, \\
& \left(N+\frac{\partial N}{\partial s} d s\right) \sin \left(\theta+\frac{\partial \theta}{\partial s} d s\right)-N \sin (\theta) \\
& \quad+\left(Q+\frac{\partial Q}{\partial s} d s\right) \cos \left(\theta+\frac{\partial \theta}{\partial s} d s\right)-Q \cos (\theta)-c \dot{u}_{y} \\
& \quad+f_{y}=d m \ddot{u}_{y},
\end{aligned}
$$

where $u_{x}$ and $u_{y}$ are displacements along the $x$-axis and the $y$-axis, respectively. $\dot{u}$ and $\ddot{u}$ are time differential variables. $f$ is an external force. Furthermore $d m=\rho A d s$ and $d s=$ $d x / \cos (\theta)$, and $\rho$ is density. $A$ is the cross-sectional area of the infinitesimal element. The relation between the shear force $Q$ and the bending moment $M$ is given as

$$
Q=\frac{\partial M}{\partial s}=\frac{\partial M}{\partial x} \cos (\theta)
$$




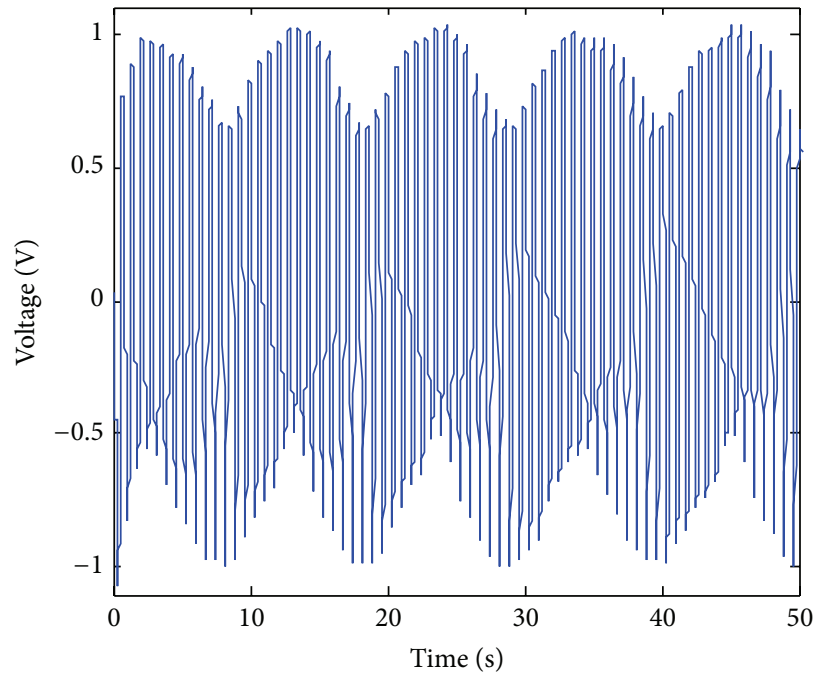

(a) Time response

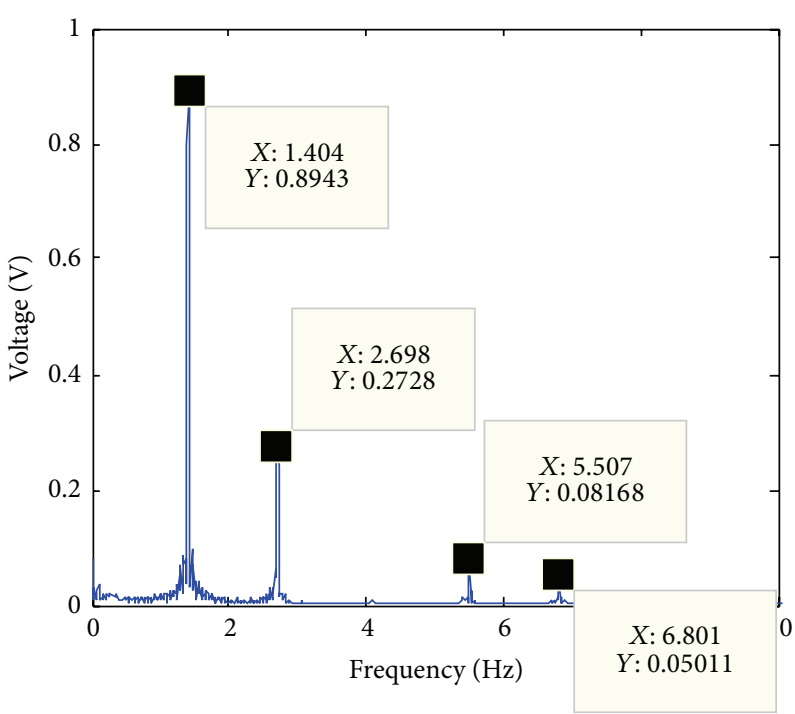

(b) Frequency response

FIGURE 2: Interharmonics response.

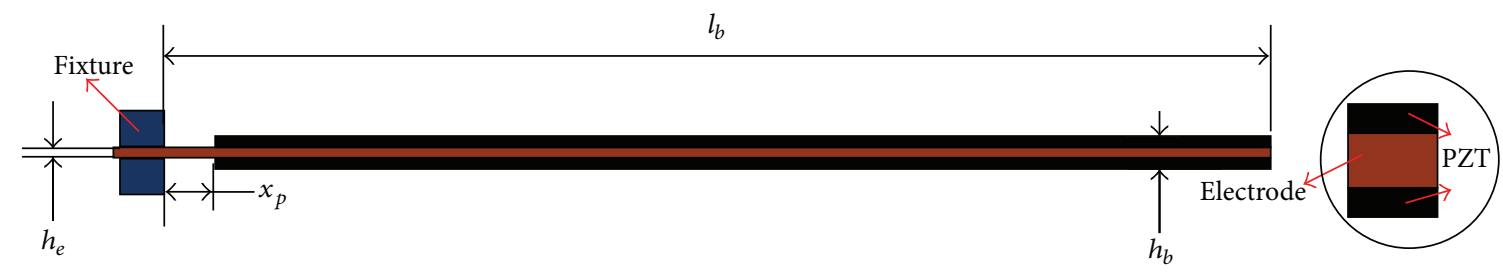

Figure 3: A piezoelectric bimorph cantilever beam.

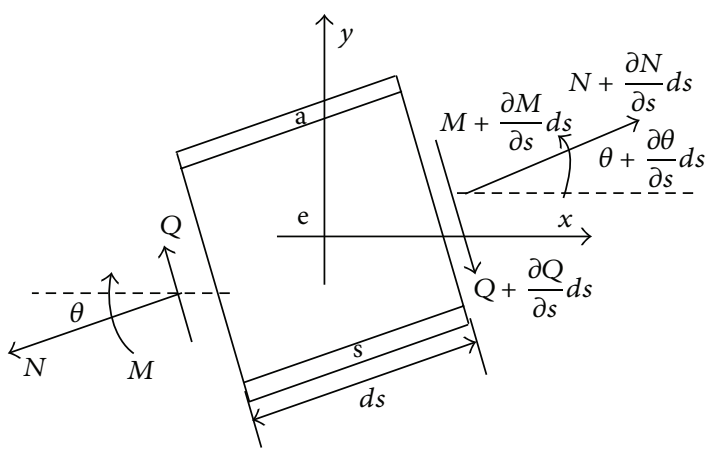

FIGURE 4: Infinitesimal element of the bimorph.

Therefore submitting $d m, d s$, and (2) into (1), and having $\theta+(\partial \theta / \partial s) d s \approx \theta,(1)$ may be transformed as

$$
\begin{aligned}
\frac{\partial}{\partial s} & {\left[N \cos (\theta)+\frac{\partial M}{\partial x} \cos (\theta) \sin (\theta)\right]+f_{x} } \\
& =\rho A \ddot{u}_{x}+c \dot{u}_{x}, \\
\frac{\partial}{\partial s} & {\left[N \sin (\theta)+\frac{\partial M}{\partial x} \cos (\theta) \cos (\theta)\right]+f_{y} } \\
& =\rho A \ddot{u}_{y}+c \dot{u}_{y} .
\end{aligned}
$$

Then, because of $\tan (\theta)=\partial u_{y} / \partial x, \tan (\theta) \approx \sin (\theta) \approx \theta$ when $\theta \rightarrow 0$. Moreover, the trigonometrical functions are expanded with the Taylor series; namely, $\cos (\theta)=1-$ $(1 / 2)(\theta)^{2}+o\left(\theta^{2}\right)$. Therefore

$$
\begin{aligned}
\sin (\theta) & \approx \frac{\partial u_{y}}{\partial x} \\
\cos (\theta) & \approx 1-\frac{1}{2}\left(\frac{\partial u_{y}}{\partial x}\right)^{2}
\end{aligned}
$$




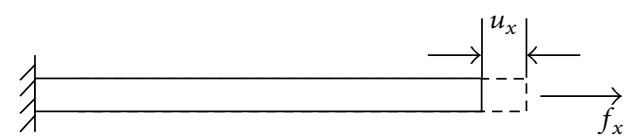

(a)

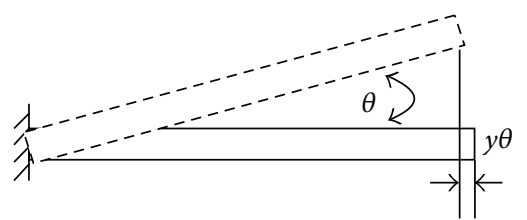

(b)

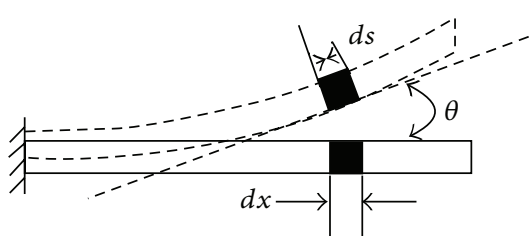

(c)

FIGURE 5: Longitudinal displacement.

In addition, the longitudinal displacement $u_{l}(x, z, t)$ consisted of three parts. The first part is the axial displacement $u_{x}(x, t)$ by the transversal force $f_{x}$ shown in Figure 5(a), Figure 5(b) displays the second part $y \cdot \tan (\theta) \approx y \theta$ caused by the cross-sectional rotation, and Figure 5(c) shows the third part $(s-x)$ from the lateral curvature; it is given as

$$
\begin{aligned}
s-x & =\int_{0}^{x} d s-x=\int_{0}^{x} \frac{d x}{\cos (\theta)}-x \\
& =\int_{0}^{x} \sqrt{\left[1+\tan ^{2}(\theta)\right]} d x-x \\
& =\int_{0}^{x} \sqrt{1+\left(\frac{\partial u_{y}}{\partial x}\right)^{2}} d x-x .
\end{aligned}
$$

Therefore, $u_{l}$ is derived as

$$
u_{l}=u_{x}+y \theta+\int_{0}^{x} \sqrt{1+\left(\frac{\partial u_{y}}{\partial x}\right)^{2}} d x-x
$$

And the corresponding stress is expressed as

$$
\sigma_{l}=E \frac{\partial u_{l}}{\partial s}=E \frac{\partial u_{l}}{\partial x} \cos (\theta),
$$

where $E=E_{e}+2 E_{a}$, where $E_{e}$ and $E_{a}$ are the Young modulus of the electrode and piezoelectric material, respectively.

Moreover, the actuating stress is generated by the applied voltage $V$ on the piezoelectric layer and is described as

$$
\begin{gathered}
\varepsilon_{1}=s_{11}^{E} \sigma_{1}+d_{31} E_{3}, \\
D_{3}=d_{31} \sigma_{1}+\varepsilon_{33}^{S} E_{3},
\end{gathered}
$$

where $A_{a}$ is the cross-sectional area of the piezoelectric actuating layer and $E_{3}=V(x, t) / h_{a}$, where $V(x, t)$ is Heaviside function. $h_{a}$ is thickness of the piezoelectric actuating layer.

Hence, with (7) and (8), the axial force is derived as

$$
\begin{aligned}
N(x, t)= & \iint_{A}\left(\sigma_{l}+\sigma_{1}\right) d A \\
= & E A\left[\frac{\partial u_{x}}{\partial x}+\frac{1}{2}\left(\frac{\partial u_{y}}{\partial x}\right)^{2}\right] \cos (\theta) \\
& +E_{a} d_{31} A_{a} \frac{V}{h_{a}}
\end{aligned}
$$

And the bending moment is gained as

$$
\begin{aligned}
M(x, t) & =\iint_{A}\left(\sigma_{l}+\sigma_{1}\right) y d A \\
& =E I \frac{\partial \theta}{\partial x} \cos (\theta)+E_{a} d_{31} A_{a} \frac{V}{2 h_{a}}\left(h_{e}+h_{a}\right),
\end{aligned}
$$

where

$$
\frac{\partial \theta}{\partial x}=[\cos (\theta)]^{2} \frac{\partial^{2} u_{y}}{\partial x^{2}}
$$

And

$$
N_{V}(x, t)=E A \frac{\partial u_{x}(x, t)}{\partial x}=E_{a} d_{31} A_{a} \frac{V(x, t)}{h_{a}} .
$$

Assuming $f_{x}=0$ and $f_{y}=0$, substitute (9) and (10) into (3), and then

$$
\begin{gathered}
\rho A \frac{\partial^{2} u_{y}}{\partial t^{2}}+c \frac{\partial u_{y}}{\partial t}+E I \frac{\partial^{4} u_{y}}{\partial x^{4}}-3 E I\left(\frac{\partial^{2} u_{y}}{\partial x^{2}}\right)^{3} \\
\approx 2 v_{N} V \frac{\partial^{2} u_{y}}{\partial x^{2}}+v_{M} \frac{\partial^{2} V}{\partial x^{2}}-v_{M} V\left(\frac{\partial^{2} u_{y}}{\partial x^{2}}\right)^{2},
\end{gathered}
$$

where

$$
\begin{aligned}
& v_{N}=\frac{E_{a} d_{31} A_{a}}{h_{a}}, \\
& v_{M}=E_{a} d_{31} A_{a} \frac{\left(h_{e}+h_{a}\right)}{2 h_{a}}, \\
& u_{y}=\phi(x) q(t),
\end{aligned}
$$

where

$$
\begin{aligned}
& \phi(x) \\
&= \cos \frac{a x}{l}-\operatorname{ch} \frac{a x}{l} \\
&+\frac{\sin (a)-\operatorname{sh}(a)}{\cos (a)+\operatorname{ch}(a)}\left(\sin \frac{a x}{l}-\operatorname{sh} \frac{a x}{l}\right), \\
& 1+\cos (a) \operatorname{ch}(a)=0, \\
& a=1.875, \\
& M \ddot{q}+C \dot{q}+K q-\alpha q^{3}=\left(\kappa+\beta q+\gamma q^{2}\right) V_{i},
\end{aligned}
$$




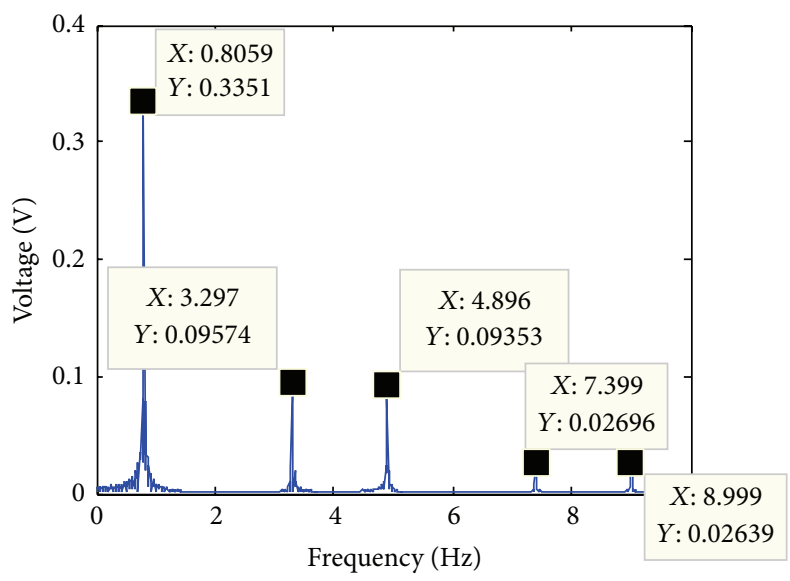

(a) Simulation

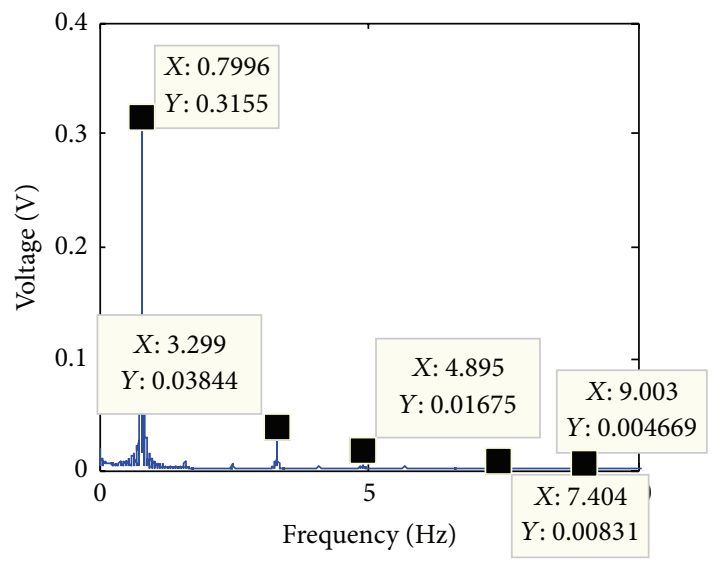

(b) Experiment

FIgURE 6: Frequency response at $0.8 \mathrm{~Hz}$.

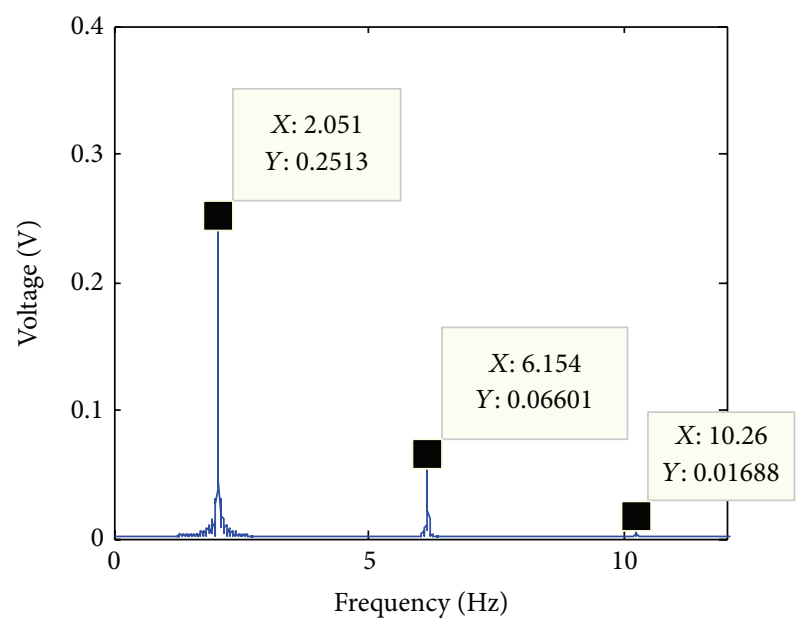

(a) Simulation

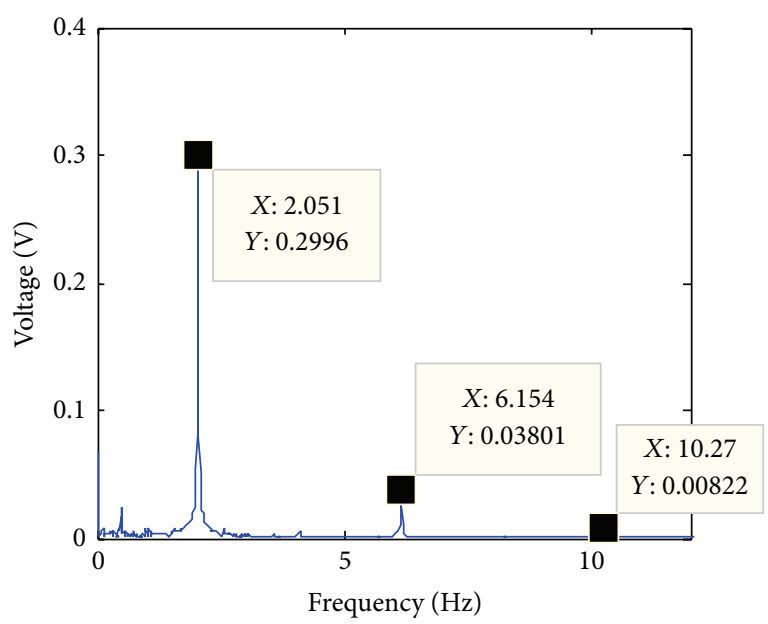

(b) Experiment

Figure 7: Frequency response at $2.05 \mathrm{~Hz}$.

where

$$
\begin{aligned}
M & =\int_{0}^{l_{b}} \rho A \varphi(x) d x, \\
C & =\int_{0}^{l_{b}} c \varphi(x) d x, \\
K & =\int_{0}^{l_{b}} E I \frac{\partial^{4} \varphi(x)}{\partial x^{4}} d x, \\
\alpha & =\int_{0}^{l_{b}} 3 E I \frac{\partial^{2} \varphi(x)}{\partial x} d x, \\
\kappa & =v_{M}, \\
\beta & =2 \int_{0}^{l_{b}} v_{N} \frac{\partial \varphi^{2}(x)}{\partial x^{2}} d x, \\
\gamma & =-\int_{0}^{l_{b}} v_{M}\left[\frac{\partial^{2} \varphi(x)}{\partial x}\right]^{2} d x, \\
V_{i} & =V\left(x_{p}, t\right) .
\end{aligned}
$$

The output voltage $V_{o}$ of the sensing layer is given in [14] Therefore, the describing set of equations of the interharmonic property for piezoelectric bimorph is expressed as

$$
\begin{aligned}
& M \ddot{q}+C \dot{q}+ K q-\alpha q^{3}+\mu V_{o}=\left(\kappa+\beta q+\gamma q^{2}\right) V_{i}, \\
&-\mu \dot{q}+c_{s} \dot{V}_{o}+\frac{V_{o}}{R}=0,
\end{aligned}
$$

where $\mu$ is the electromechanical coupling, $c_{s}$ is the effective capacitance of the piezoelectric sensing layers, and $R$ is the electric load and is equal to $R_{l}\left(1-r \sin 2 \pi f_{R}\right)$, where $R_{l}$ is a load's resistance, $r$ is a corresponding coefficient, and $f_{R}$ is the load's frequency.

\section{Results and Discussions}

Based on the constructed model (17), the simulation and experiment results are shown in Figures 6-9 with the Fast Fourier Transform Algorithm. Figure 6 gives the frequency response when the applied voltage frequency of the actuating piezoelectric layer is $0.8 \mathrm{~Hz}$. The frequencies of simulation 


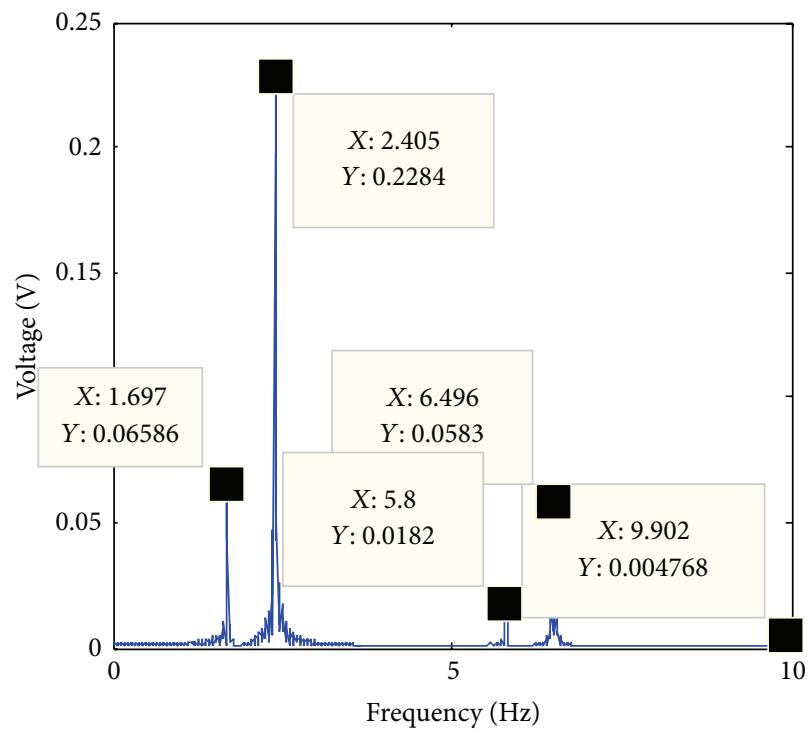

(a) Simulation

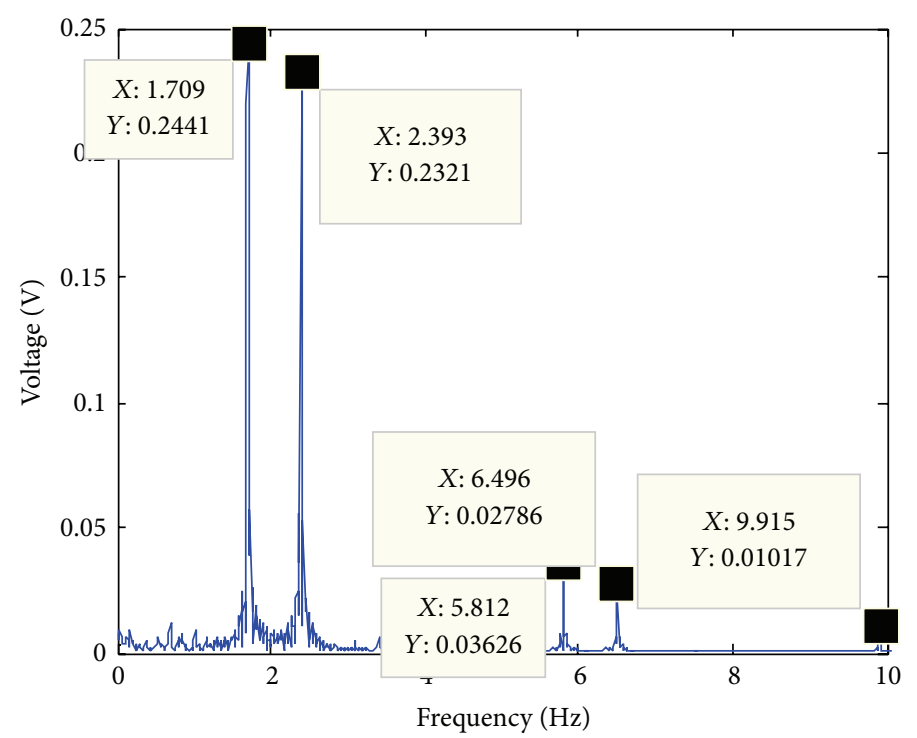

(b) Experiment

FIGURE 8: Frequency response at $2.4 \mathrm{~Hz}$.

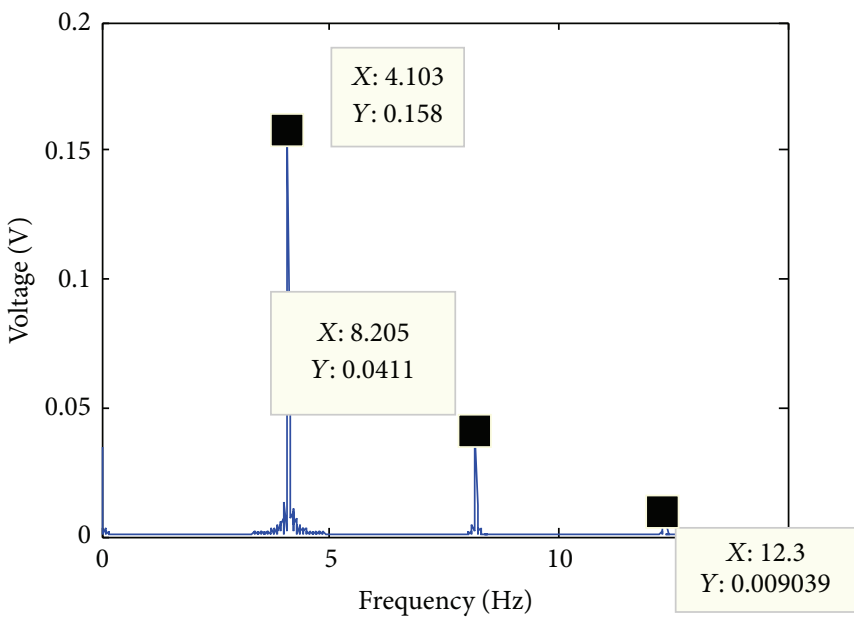

(a) Simulation

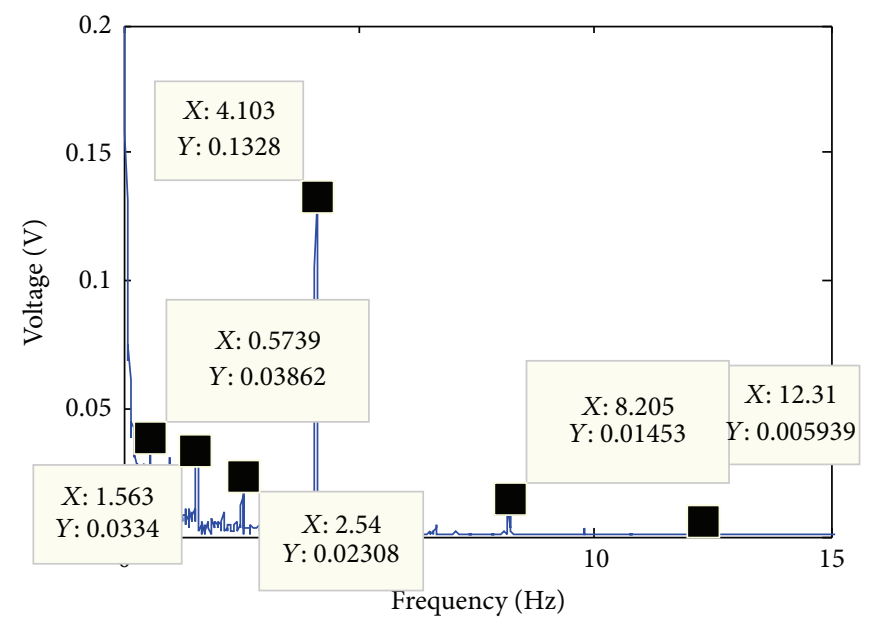

(b) Experiment

FIGURE 9: Frequency response at $4.1 \mathrm{~Hz}$.

response in Figure 6(a) are $0.8059 \mathrm{~Hz}, 3.297 \mathrm{~Hz}, 4.896 \mathrm{~Hz}$, $7.399 \mathrm{~Hz}$, and $8.999 \mathrm{~Hz}$ while the response frequencies of experiment in Figure 6(b) are $0.7996 \mathrm{~Hz}, 3.299 \mathrm{~Hz}, 4.895 \mathrm{~Hz}$, $7.404 \mathrm{~Hz}$, and $9.003 \mathrm{~Hz}$. Moreover, Figure 7 shows the frequency response at the input voltage frequency $2.05 \mathrm{~Hz}$. The simulation output frequencies in Figure 7 (a) are $2.051 \mathrm{~Hz}$, $6.154 \mathrm{~Hz}$, and $10.26 \mathrm{~Hz}$ and the experiment output frequencies in Figure $7(\mathrm{~b})$ are $2.051 \mathrm{~Hz}, 6.154 \mathrm{~Hz}$, and $10.27 \mathrm{~Hz}$. Furthermore, Figure 8 displays the frequency response when the actuating voltage frequency is $2.4 \mathrm{~Hz}$. The response frequencies with simulation in Figure $8(\mathrm{a})$ are $1.679 \mathrm{~Hz}$, $2.405 \mathrm{~Hz}, 5.8 \mathrm{~Hz}, 6.496 \mathrm{~Hz}$, and $9.902 \mathrm{~Hz}$ while the output response frequencies with experiment are $1.709 \mathrm{~Hz}, 2.393 \mathrm{~Hz}$, $5.812 \mathrm{~Hz}, 6.496 \mathrm{~Hz}$, and 9.915 Hz in Figure 8(b). Finally, when the applied voltage frequency of the actuating piezoelectric layer is $4.1 \mathrm{~Hz}$, the output response voltage frequencies are given in Figure 9. The simulation output voltage frequencies in Figure 9(a) are $4.103 \mathrm{~Hz}, 8.205 \mathrm{~Hz}$, and $12.3 \mathrm{~Hz}$ and the experiment output voltage frequencies are $0.5739 \mathrm{~Hz}$, $0.989 \mathrm{~Hz} 1.563 \mathrm{~Hz}, 2.54 \mathrm{~Hz}, 4.103 \mathrm{~Hz}, 8.205 \mathrm{~Hz}$, and $12.31 \mathrm{~Hz}$ in Figure 9(b).

Therefore, from above discussion on comparison between the simulation and experiment results, the law of the output voltage frequency from the sensing piezoelectric layer is summarized from the four set results at different input voltage frequencies and is shown in Table 1 . The output voltage frequencies are $f_{i}, f_{R} \pm f_{i}, 2 f_{R} \pm f_{i}, 3 f_{R} \pm f_{i}, \ldots$, and $f_{R}=4.10 \mathrm{~Hz}$. If $f_{R}$ is not equal to $f_{i}$, the interharmonics will appear. When 


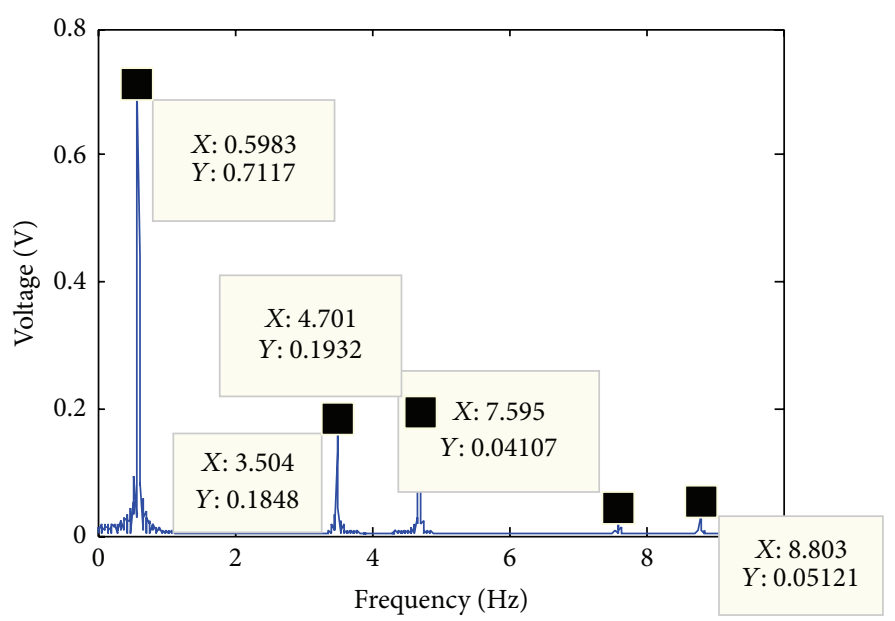

(a) Simulation

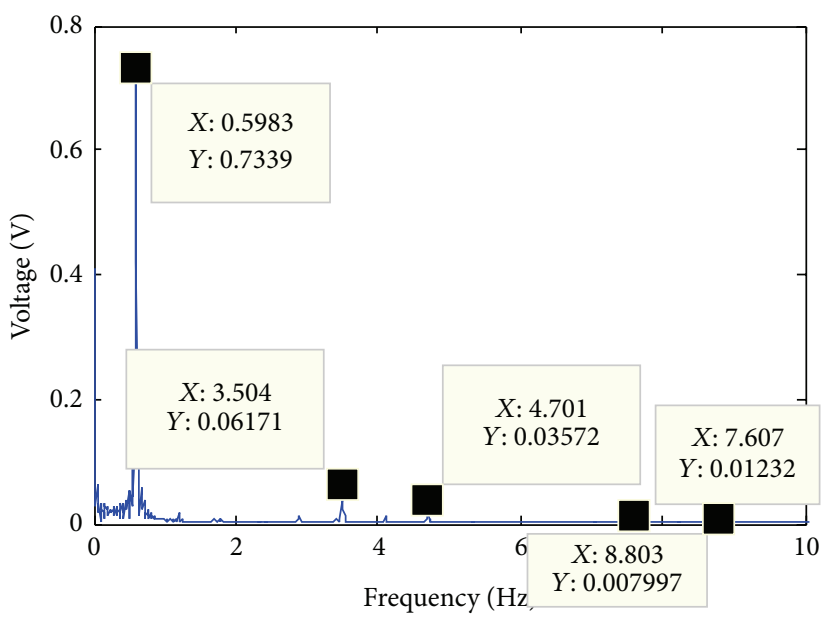

(b) Experiment

Figure 10: Frequency response at $0.6 \mathrm{~Hz}$.

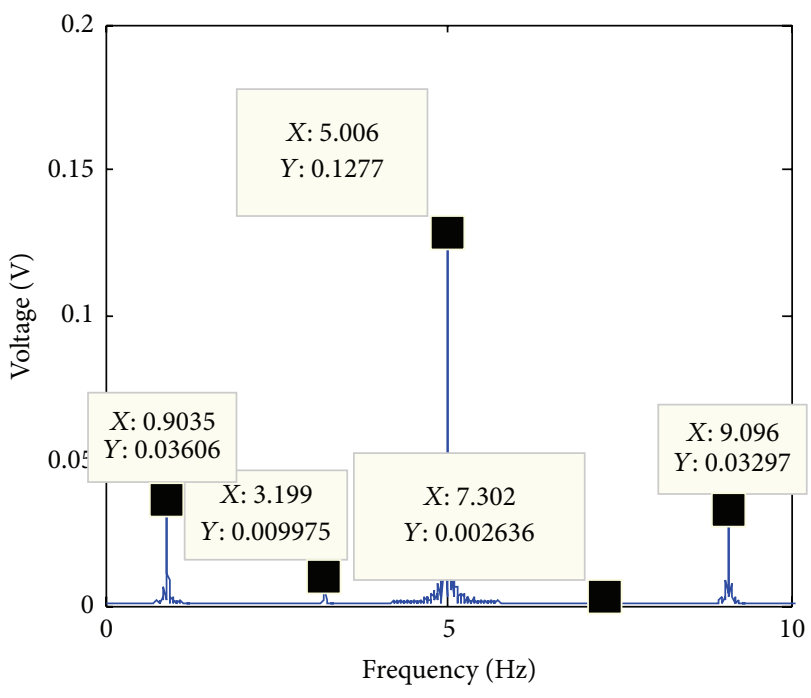

(a) Simulation

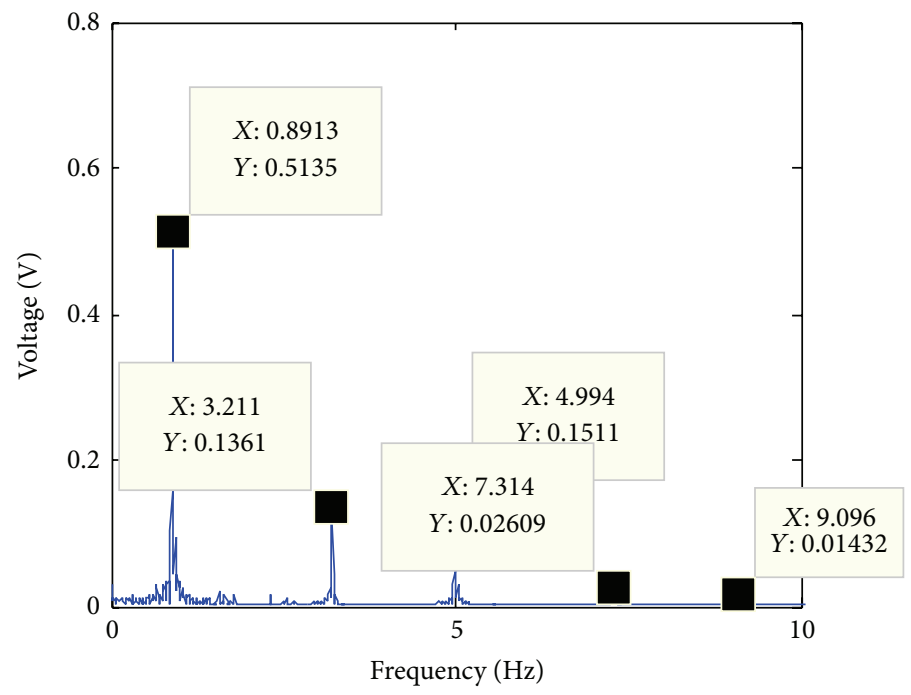

(b) Experiment

FIGURE 11: Frequency response at $5 \mathrm{~Hz}$.

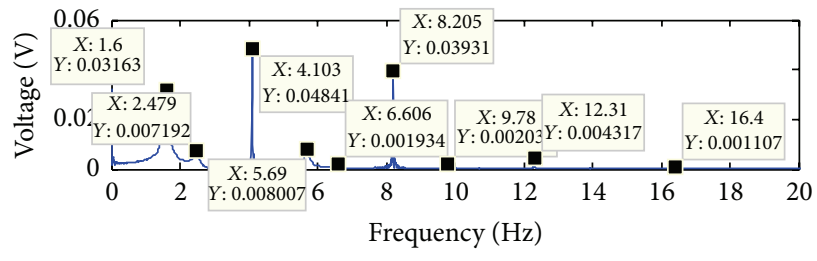

(a) Simulation

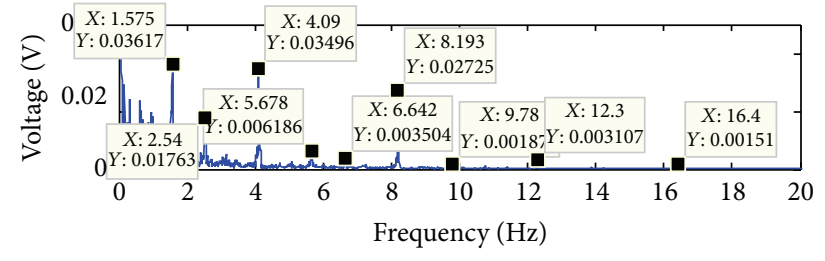

(b) Experiment

FIGURE 12: Frequency response at $8.2 \mathrm{~Hz}$.

$f_{R}$ is equal to $f_{i}$, the resonance phenomenon will happen. Then, that output voltage frequency $f_{o}$ may be deduced at input frequencies $0.6 \mathrm{~Hz}, 5 \mathrm{~Hz}$, and $8.2 \mathrm{~Hz}$. Shown in Figures $10-12$, the frequency responses by simulations are compared with experiments. And the compared frequency results are given in Tables 2 and 3. From Figure 10, when the input voltage is applied with a sinusoidal signal at amplitude $4.5 \mathrm{~V}$ and frequency $0.6 \mathrm{~Hz}$, the frequencies of output response are $0.5983 \mathrm{~Hz}, 3.504 \mathrm{~Hz}, 4.701 \mathrm{~Hz}, 7.595 \mathrm{~Hz}$, and $8.803 \mathrm{~Hz}$ by simulations and $0.5983 \mathrm{~Hz}, 3.504 \mathrm{~Hz}, 4.701 \mathrm{~Hz}, 7.607 \mathrm{~Hz}$, 
TABLE 1: Output frequency of voltage response.

\begin{tabular}{llccccccc}
\hline \multirow{2}{*}{$f_{i}(\mathrm{~Hz})$} & & \multicolumn{7}{c}{$f_{o}(\mathrm{~Hz})$} \\
& $f_{\text {sup1 }}$ & $f_{\text {sup2 }}$ & $f_{\text {sup3 }}$ & $f_{\text {sup4 }}$ & $f_{1}$ & $f_{\text {sub1 }}$ & $f_{\text {sub2 }}$ & $f_{\text {sub3 }}$ \\
\hline 0.80 & & & & & 0.80 & 3.30 & 4.90 & 7.40 \\
2.05 & & & & & 2.05 & 6.15 & 10.26 & \\
2.40 & & & & 1.70 & 2.40 & 5.80 & 6.50 & 9.90 \\
4.10 & 0.57 & 0.99 & 1.56 & 2.54 & 4.10 & 8.20 & 12.30 & \\
\hline
\end{tabular}

TABLE 2: Simulation output frequency.

\begin{tabular}{llllllllll}
\hline \multirow{2}{*}{$f_{i}(\mathrm{~Hz})$} & & \multicolumn{10}{c}{$f_{o}(\mathrm{~Hz})$} & & & \\
& $f_{\text {sup } 1}$ & $f_{\text {sup } 2}$ & $f_{\text {sup3 }}$ & $f_{\text {sup } 4}$ & $f_{1}$ & $f_{\text {sub1 } 1}$ & $f_{\text {sub2 } 2}$ & $f_{\text {sub3 }}$ & $f_{\text {sub4 }}$ \\
\hline 0.6 & & & & & 0.598 & 3.504 & 4.701 & 7.595 & 8.803 \\
5.0 & & & & 0.9035 & 3.199 & 5.006 & 7.302 & 9.096 & \\
8.2 & 1.600 & 2.479 & 4.103 & 5.690 & 6.606 & 8.205 & 9.780 & 12.310 & 16.40 \\
\hline
\end{tabular}

and $8.803 \mathrm{~Hz}$ by experiments, respectively. Similarly, From Figure 11, when the input voltage is applied with a sinusoidal signal at amplitude $4.5 \mathrm{~V}$ and frequency $5 \mathrm{~Hz}$, the frequencies of output response are $0.9035 \mathrm{~Hz}, 3.199 \mathrm{~Hz}, 5.006 \mathrm{~Hz}$, $7.302 \mathrm{~Hz}$, and $9.096 \mathrm{~Hz}$ by simulations and $0.8913 \mathrm{~Hz}, 3.211 \mathrm{~Hz}$, $4.994 \mathrm{~Hz}, 7.314 \mathrm{~Hz}$, and $9.096 \mathrm{~Hz}$ by experiments, respectively. And from Figure 12, when the input voltage is applied with a sinusoidal signal at amplitude $4.5 \mathrm{~V}$ and frequency $8.2 \mathrm{~Hz}$, the frequencies of output response are $1.6 \mathrm{~Hz}, 2.479 \mathrm{~Hz}, 4.103 \mathrm{~Hz}$, $5.69 \mathrm{~Hz}, 6.606 \mathrm{~Hz}, 8.205 \mathrm{~Hz}, 9.78 \mathrm{~Hz}, 12.31 \mathrm{~Hz}$, and $16.4 \mathrm{~Hz}$ by simulations and $1.575 \mathrm{~Hz}, 2.54 \mathrm{~Hz}, 4.09 \mathrm{~Hz}, 5.678 \mathrm{~Hz}$, $6.642 \mathrm{~Hz}, 8.193 \mathrm{~Hz}, 9.78 \mathrm{~Hz}, 12.3 \mathrm{~Hz}$, and $16.4 \mathrm{~Hz}$ by experiments, respectively. The corresponding output frequency results are displayed in Table 2 with simulations and Table 3 with experiments, respectively.

Therefore, the interharmonics property of the piezoelectric bimorph is reflected not only in the smaller frequency but also in the higher frequency of the output response than that of input voltage. Moreover the theoretical model of the piezoelectric bimorph is verified effectively by simulations and experiments. Furthermore, the output simulation frequencies are almost the same as the output experimental frequencies. Especially when the input voltage is at frequency $4.1 \times n \mathrm{~Hz}$ $(n=1,2,3, \ldots)$, the output response voltage has resonance and lower frequency interharmonics.

\section{Conclusions}

In the paper, a theoretical model is proposed for a piezoelectric bimorph to describe the interharmonic property. And the dynamic model is constructed by the longitudinal and transverse coupling theory for the piezoelectric bimorph cantilevered beam. Moreover, with the simulation and experiment results, the theoretical model is validated to express the nonlinear characteristic. Furthermore, in future work, the theoretical model will be used to design a displacement compensating controller for the piezoelectric bimorph cantilevered beam.
TABLE 3: Experiment output frequency.

\begin{tabular}{llllllllll}
\hline \multicolumn{1}{l}{$f_{i}(\mathrm{~Hz})$} & $f_{\text {sup1 }}$ & $f_{\text {sup2 }}$ & $f_{\text {sup3 }}$ & $f_{\text {sup4 }}$ & $f_{1}$ & $f_{\text {sub1 }}$ & $f_{\text {sub2 }}$ & $f_{\text {sub3 }}$ & $f_{\text {sub4 }}$ \\
\hline 0.6 & & & & & 0.598 & 3.504 & 4.701 & 7.607 & 8.803 \\
5.0 & & & & 0.891 & 3.211 & 4.994 & 7.314 & 9.096 & \\
8.2 & 1.575 & 2.540 & 4.090 & 5.678 & 6.642 & 8.193 & 9.780 & 12.300 & 16.400 \\
\hline
\end{tabular}

\section{Competing Interests}

The authors declare that there is no conflict of interests regarding the publication of this paper.

\section{Acknowledgments}

This work was supported by the Scientific Research Startup Foundation of Shanghai University of Engineering Science and the Shanghai Science and Technology commission local colleges' capacity building project: 14110501200.

\section{References}

[1] X. Hou, "Modeling and characterization of a bimorph impedance transducer," Journal of Sound and Vibration, vol. 324, no. 3-5, pp. 608-621, 2009.

[2] M. F. Lumentut and I. M. Howard, "Analytical and experimental comparisons of electromechanical vibration response of a piezoelectric bimorph beam for power harvesting," Mechanical Systems and Signal Processing, vol. 36, no. 1, pp. 66-86, 2013.

[3] C. J. Morris and F. K. Forster, "Optimization of a circular piezoelectric bimorph for a micropump driver," Journal of Micromechanics and Microengineering, vol. 10, no. 3, pp. 459-465, 2000.

[4] S. Y. Wang, "A finite element model for the static and dynamic analysis of a piezoelectric bimorph," International Journal of Solids and Structures, vol. 41, no. 15, pp. 4075-4096, 2004.

[5] G. Wang, "Analysis of bimorph piezoelectric beam energy harvesters using Timoshenko and Euler-Bernoulli beam theory," Journal of Intelligent Material Systems and Structures, vol. 24, no. 2, pp. 226-239, 2013.

[6] P. J. Costa Branco and J. A. Dente, "On the electromechanics of a piezoelectric transducer using a bimorph cantilever undergoing asymmetric sensing and actuation," Smart Materials and Structures, vol. 13, no. 4, pp. 631-642, 2004.

[7] J. M. Renno and D. J. Inman, "An experimentally verified model of a membrane mirror strip actuated using piezoelectric bimorph," Journal of Vibration and Acoustics, vol. 129, no. 5, pp. 631-640, 2007.

[8] L. Zhang, K. A. Williams, and Z. Xie, "Development and validation of an enhanced coupled-field model for PZT cantilever bimorph energy harvester," Mathematical Problems in Engineering, vol. 2013, Article ID 980161, 10 pages, 2013.

[9] S. Rafique and P. Bonello, "Experimental validation of a distributed parameter piezoelectric bimorph cantilever energy harvester," Smart Materials and Structures, vol. 19, no. 9, article 094008, 2010.

[10] A. Erturk and D. J. Inman, "An experimentally validated bimorph cantilever model for piezoelectric energy harvesting from base excitations," Smart Materials and Structures, vol. 18, no. 2, Article ID 025009, 19 pages, 2009. 
[11] X. J. Dong, Z. K. Peng, H. X. Hua, and G. Meng, "Modeling of the through-the-thickness electric potentials of a piezoelectric bimorph using the spectral element method," Sensors, vol. 14, no. 2, pp. 3477-3492, 2014.

[12] C. Zhang, J. Qiu, Y. Chen, and H. Ji, "Modeling hysteresis and creep behavior of macrofiber composite-based piezoelectric bimorph actuator," Journal of Intelligent Material Systems and Structures, vol. 24, no. 3, pp. 369-377, 2013.

[13] Y.-L. Kuo, "Attitude control of miniature spacecraft under the gravitational effect using a hub-bimorph mechanism," Journal of Vibration and Control, vol. 19, no. 12, pp. 1822-1832, 2013.

[14] R. Masana and M. F. Daqaq, "Energy harvesting in the superharmonic frequency region of a twin-well oscillator," Journal of Applied Physics, vol. 111, no. 4, Article ID 044501, 2012.

[15] M. Ferrari, M. Baù, F. Cerini, and V. Ferrari, "Impact-enhanced multi-beam piezoelectric converter for energy harvesting in autonomous sensors," Procedia Engineering, vol. 47, pp. 418-421, 2012.

[16] S. Djurovic, D. S. Vilchis-Rodriguez, and A. C. Smith, "Supply induced interharmonic effects in wound rotor and doubly-fed induction generators," IEEE Transactions on Energy Conversion, vol. 30, no. 4, pp. 1397-1408, 2015.

[17] K. S. Smith and L. Ran, "Torsional resonance risk management in islanded industrial power systems supplying large VFDs," IEEE Transactions on Industry Applications, vol. 44, no. 6, pp. 1841-1850, 2008. 


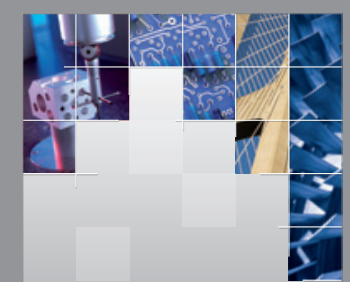

\section{Enfincering}
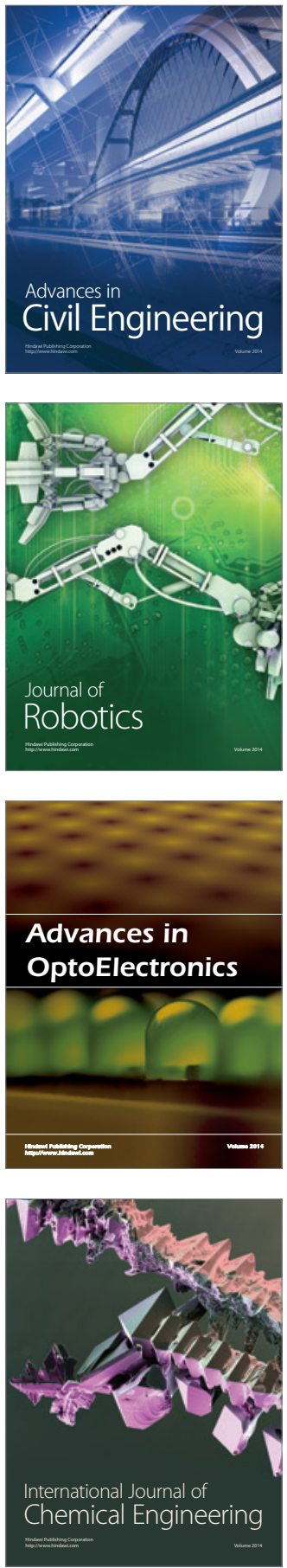

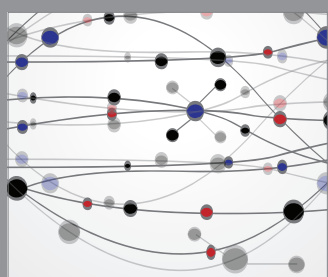

The Scientific World Journal

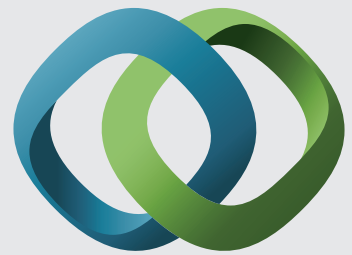

\section{Hindawi}

Submit your manuscripts at

http://www.hindawi.com
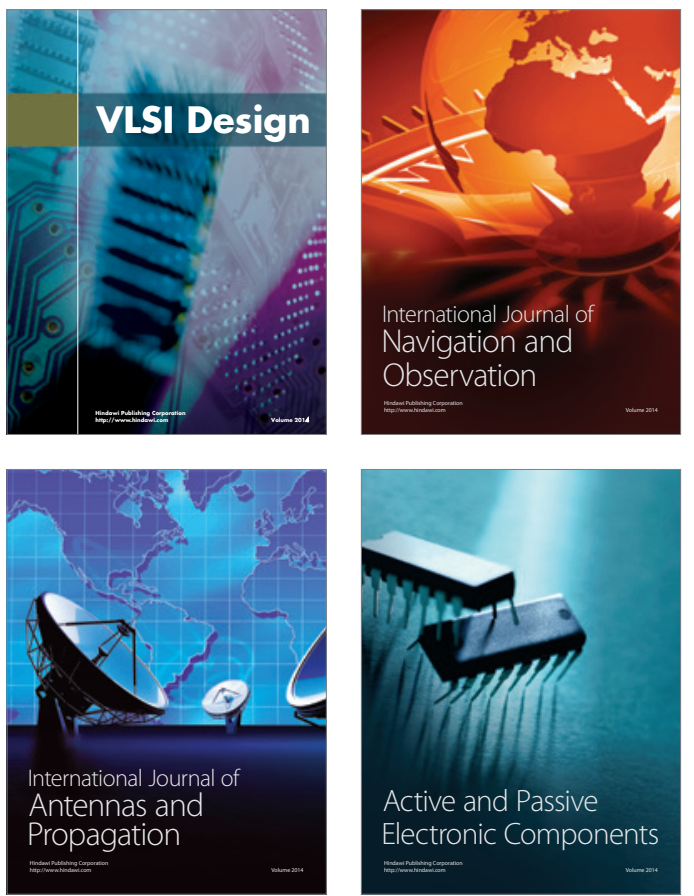
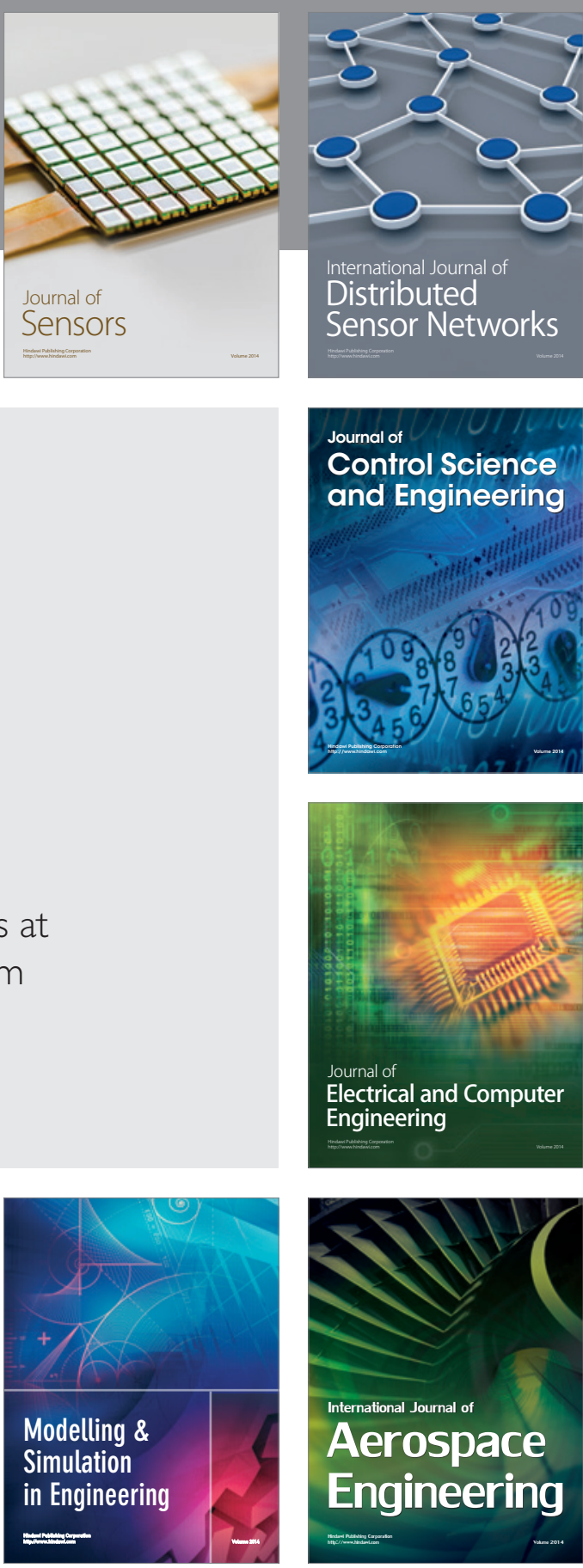

International Journal of

Distributed

Sensor Networks

Journal of

Control Science

and Engineering
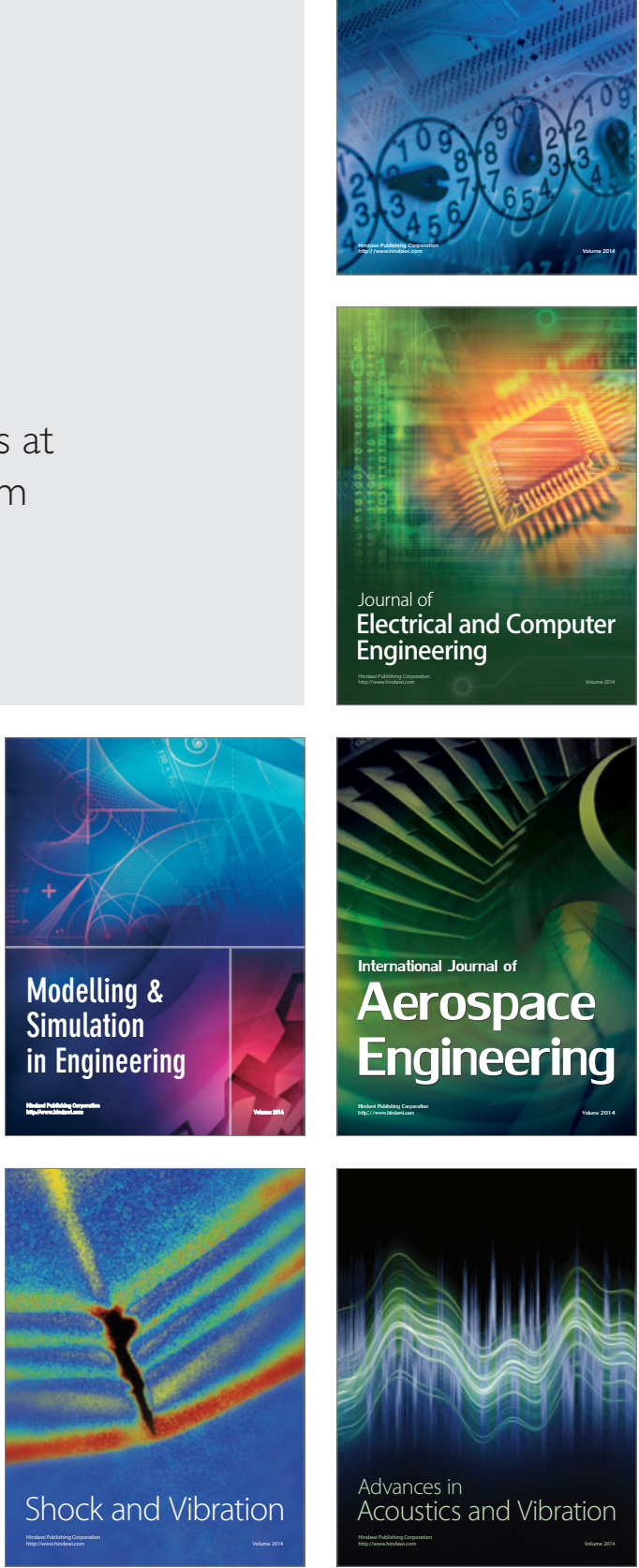